\title{
透光性YAGセラミックスの近赤外熱光学特性
}

梅津 佳祐 ${ }^{1}$ ，古瀬 裕章 ${ }^{1}$, 安原 亮 $^{2}$, 曽根 宏靖 ${ }^{1}$ ，川村 みどり ${ }^{1}$ ，平賀 啓二郎 ${ }^{1}$

${ }^{1}$ 北見工業大学 $($ 厂090-8507 北海道北見市公園町165)

${ }^{2}$ 核融合科学研究所 ( T 509-5292 岐阜県土岐市下石町322-6)

\section{Thermo-optic Characteristics of Transparent Ceramic YAG in the Near Infrared Region}

\author{
Keisuke UMETSU ${ }^{1}$, Hiroaki FURUSE ${ }^{1}$, Ryo YASUHARA ${ }^{2}$, Hiroyasu SONE ${ }^{1}$, Midori KAWAMURA ${ }^{1}$, \\ and Keijiro HIRAGA ${ }^{1}$ \\ ${ }^{1}$ Kitami Institute of Technology, 165 Koen-cho, Kitami, Hokkaido 090-8507 \\ ${ }^{2}$ National Institute for Fusion Science, 322-6 Oroshi-cho, Toki, Gifu 509-5292
}

(Received January 31, 2017)

\begin{abstract}
The thermo-optic coefficient $d n / d T$ at a wavelength of $1064 \mathrm{~nm}$ was measured in a transparent ceramic yttrium aluminum garnet (YAG) between room temperature and $430 \mathrm{~K}$. The values of $d n / d T$ at $300 \mathrm{~K}$ and $400 \mathrm{~K}$ were $7.43 \times 10^{-6} 1 / \mathrm{K}$ and $10.0 \times 10^{-6} 1 / \mathrm{K}$, respectively. In addition, the $d n / d T$ at $632.8 \mathrm{~nm}$ and thermal expansion coefficient were also measured at the same temperature range.
\end{abstract}

Key Words: Laser material, Thermal effect, Optical property

1.はじめに

$\mathrm{Y}_{3} \mathrm{Al}_{5} \mathrm{O}_{12}(\mathrm{YAG})$ は高い機械的, 熱的, 光学的性質を有 しており，高出力レーザー材料の代表的な母材として幅 広く用いられている．近年YAG単結晶と同等の光学品 質を有し，かつ $10 \mathrm{~cm}$ 角以上の大口径化が可能な高品質 透光性YAGセラミックスが開発され，これによる次世 代高出力レーザーの開発が盛んに行われている ${ }^{1-3)}$.

高出力MOPA (Master Oscillator Power Amplifier) レー ザー開発に扔ける重要課題の一つは, 媒質内で生じる熱 収差や熱複屈折等の低減である。これらの熱問題は主に 媒質内の温度勾配に起因するため, 適した材料形状の選 択と冷却機構の導入が重要であり, 設計段階での詳細な 熱解析が高出力レーザー開発では必須である.

熱解析に扔いて, 熱伝導率 $K$, 熱澎張係数 $\alpha$, 熱光学 係数 $d n / d T$ は特に重要な物性值である。透光性YAGセラ ミックスの場合，室温に㧍けるこれらの值は報告されて 打り，それぞれ $K=10.1 \mathrm{~W} / \mathrm{mK}^{4)}, \alpha=7.00 \times 10^{-6} 1 / \mathrm{K}^{5)}$, $\left.d n / d T(632.8 \mathrm{~nm})=8.41 \times 10-61 / \mathrm{K}^{6}\right)$ である. 一方, 強励起 により著しい温度上昇が懸念される産業用高出力レー ザーや，低温冷却型Yb:YAGレーザー等, 多様な高出力 YAGレーザーに対して詳細な熱解析を行うためには上 述の熱物性值の温度依存性を考慮する必要がある。

YAGセラミックスに㧍ける熱伝導率は 5 Kから 473 Kの 広く温度範囲で測定されている ${ }^{4,8-10)}$ 。また我々はHe-Ne レーザー $(632.8 \mathrm{~nm})$ によるフイゾー干渉を利用し, YAG セラミックスの熱膨張率, 熱光学係数を50-600 Kの温度
領域に対して調查した6,11)。そして, これらの物性值は 温度に対して増加し, 温度特性が単結晶体と同等である ことを示した。

一方，YbやNdを活性元素とする高出力レーザーは波 長 $1 \mu \mathrm{m}$ 帯で動作するため, $632.8 \mathrm{~nm}$ の熱光学係数を用い た場合，光線追跡に打いてずれが生じる可能性がある． 波長1 $\mu \mathrm{m}$ 帯に扔けるYAGの熱光学係数は, 単結晶にお いて低温域では調查されているが ${ }^{22}$, 室温以上では報告 が少ない.

したがって本研究では主に産業用高出力YAGレー ザーの設計を念頭に, 透光性YAGセラミックスの波 長1064 nmに扔ける熱光学係数を室温から $430 \mathrm{~K}$ の温度領 域で調查した。また熱膨張倸数抒よび熱光学係数 $(632.8 \mathrm{~nm})$ の測定も行い, 熱レンズ効果について検討し た.

\section{2. 実験方法}

本研究ではフィゾー干渉を用いて熱膨張係数, 熱光学 係数の測定を行った。測定に用いた透光性YAGセラ ミックス(神島化学工業)の写真をFig. 1 に示す。試料 (A) は接合により一体化したコンポジットYAGセラミッ クスであり，両端面が光学研磨された3つのYAGセラ ミックスから構成されている。試料(B) は厚み約 $3 \mathrm{~mm}$ の YAG七ラミックである. 熱膨張係数㧍よび熱光学係数 $(632.8 \mathrm{~nm})$ の測定には試料 $(A)$ を，また熱光学係数 $(1064 \mathrm{~nm})$ の測定には試料(B)をそれぞれ用いた。 


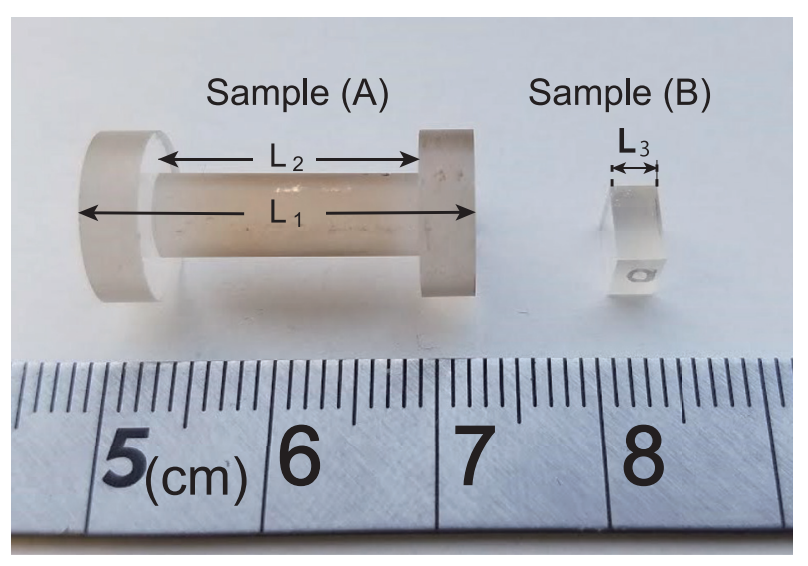

Fig. 1 Photograph of the undoped ceramic YAG. Sample (A) is the diffusion bonded ceramic YAG for measuring the thermal expansion coefficient. Sample (B) is for the measurement of the thermo-optic coefficient.

試料(A)の場合, レーザー光を拡大平行光とした後に 照射することによってYAG中心部の両端面および接合部 内面からの反射光がそれぞれ干渉する. 試料を真空中に 置いた場合，各干涉を形成する反射面間の光路長はそれ ぞれ $n L_{1}, L_{2}$ と表すことができる。ここで $L_{1}=15.6 \mathrm{~mm}$, $L_{2}=22.4 \mathrm{~mm}$ であり,$n=1.8293$ は波長 $632.8 \mathrm{~nm}$ における YAGセラミックスの屈折率である.

試料に温度変調 $\Delta T$ をえた場合, 熱光学効果によっ て各干渉縞に光路長変化 $\Delta\left(2 n L_{1}\right), \Delta\left(2 L_{2}\right)$ が生じ, 温度 に対する変化率 $\gamma_{1}, \gamma_{2}$ は以下となる.

$$
\begin{gathered}
\gamma_{1}=\frac{1}{n L_{1}} \frac{d\left(n L_{1}\right)}{d T}=\alpha+\frac{1}{n} \frac{d n}{d T} \\
\gamma_{2}=\frac{1}{L_{2}} \frac{d L_{2}}{d T}=\alpha
\end{gathered}
$$

真空部を伝搬する(2)式の場合は, 屈折率の温度変化に よる影響を受けず, 熱膨張係数 $\alpha か ゙$ 求まる。このよう に, 試料(A)のような一体型試料を用いることで熱膨張 係数および熱光学係数を同時に計測することが可能と なる。

\section{$2.11 \mu \mathrm{m}$ 帯の熱光学係数の測定}

Fig. 2 に近赤外熱光学係数の実験系を示す. $1 \mu \mathrm{m}$ 帯の 熱光学係数を調べるために，波長1064 nmのDFB (Distributed Feedback) レーザーをプローブ光に使用し た. コヒーレンス長の問題から, 測定には試料 $(\mathrm{B})\left(L_{3}=\right.$ $3.07 \mathrm{~mm}$ )を用いた。 真空チャンバー内の銅ホルダに試 料を設置し, 熱電対を試料に接着した。接着には銀ぺー ストを使用した。プローブ光を拡大・平行化した後に試 料へ照射し, 両端面の反射光を光検出器に導入し, デー タロガーを用いて干渉光強度と試料温度を測定した。光 路長差 $\Delta\left(2 n L_{1}\right)$ はヒーターを用いて試料に温度変調 $\Delta T$ を 与えて測定した。本測定では昇温速度を $4.5 \mathrm{~K} / \mathrm{min} に$ 設

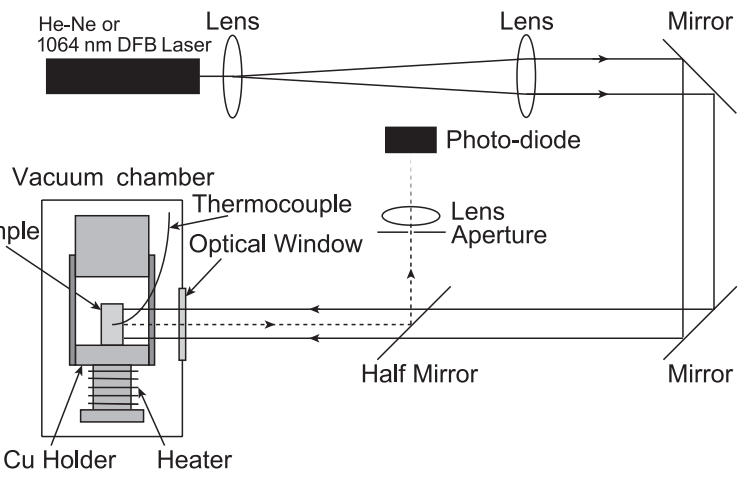

Fig. 2 Experimental setup of the interferometer for Sample (B).

定した，測定温度範囲は293-433 Kであり， $\Delta T=10 \mathrm{~K}$ 間 隔での変化率を見積もった。

2.2節で述べるように，熱光学係数 $(1064 \mathrm{~nm})$ の算出に は試料 (A) で測定した熱膨張係数を用いた。なお，波 長1064 nmにおける屈折率の值は $n=1.816348^{\dagger を}$ 使用し た。

Fig. 3 は温度範囲300-400 Kにおける干渉信号強度変 化の測定例である。Fig. 3(b)に示すように，測定デー夕 を $\Delta T=10 \mathrm{~K}$ 毎に区切り，それぞれ正弦曲線でフィッ ティングして $\Delta\left(2 n L_{1}\right) / \Delta T$ を求めた。同様の測定を複数回 繰り返し，各温度での平均值を算出した。また比較のた め, He-Neレーザーを用いて試料 (A), (B) 両方に対して 熱光学係数 $(632.8 \mathrm{~nm})$ を調査した.

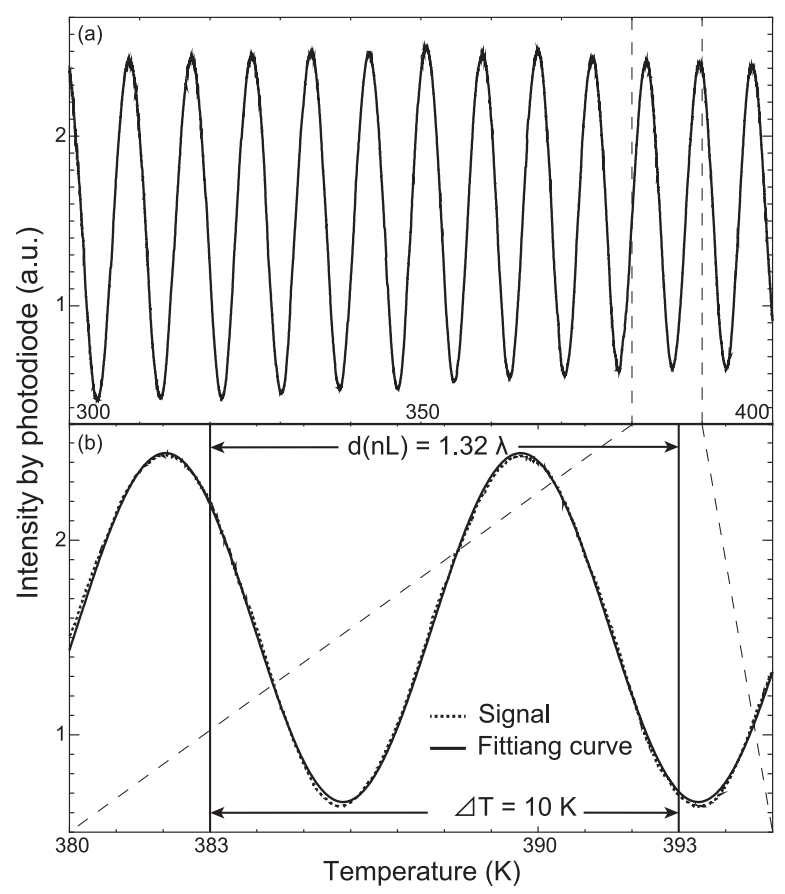

Fig. 3 Shift in the interference intensity (a) measured between 300 and $400 \mathrm{~K}$ and (b) an extract between 383 and $393 \mathrm{~K}$. 


\section{2 熱膨張係数の測定}

300-600 Kにおける透光性YAGセラミックスの熱膨張 係数についてはFuruseら ${ }^{11)}$ が報告している。同報告で は，温度測定点が無酸素銅の試料ホルダであり，また室 温付近での昇温速度が $10 \mathrm{~K} / \mathrm{min}$ と比較的速い。そのため 試料ホルダとYAGとの間に温度差が生じている可能性 がある。本研究では試料ホルダではなくYAGセラミッ クス試料の温度を熱電対で直接測定し, 熱膨張係数の結 果の違いを確認した。

本研究では試料 $(\mathrm{A})$ を用いて熱膨張係数の測定を行っ た。測定には2.1節の測定と同じ実験系を用いた。熱電 対を試料および銅ホルダに設置し, 上記文献11)の結果 との比較を行った。昇温速度は $4.8 \mathrm{~K} / \mathrm{min} に$ 設定した。 プローブ光にはHe-Neレーザーを用いた。

\section{3. 実験結果と考察}

\section{1 熱膨張係数の解析結果}

Fig. 4 の○およ゙○はそれぞれ熱電対をYAG試料およ び銅ホルダに取り付けて計測した温度から熱膨張係数を 解析した結果を示す。また実線は熱膨張係数のフィッ ティング曲線を示している.

Fig. 4 より, YAG試料の測定温度から解析を行った結 果は, 銅ホルダの測定温度から解析した結果よりも 約 $2.5 \%$ 大きい值を示した。この理由は測定時にYAG試 料と銅ホルダの間に温度差が生じており, 銅ホルダの方 が昇温速度が早いために熱膨張係数が小さく見積もられ たためである。したがって, 試料温度から得られた熱膨 張係数 $(\mathbf{O})$ がより正確な值と考えられる。また銅ホルダ から解析した熱膨張係数の結果は、昇温速度 $10 \mathrm{~K} / \mathrm{min}$ で 測定された文献11)の結果とほほ同じ值を示した。

本研究で得られた熱膨張係数は室温において $6.4 \times 10^{-6}$

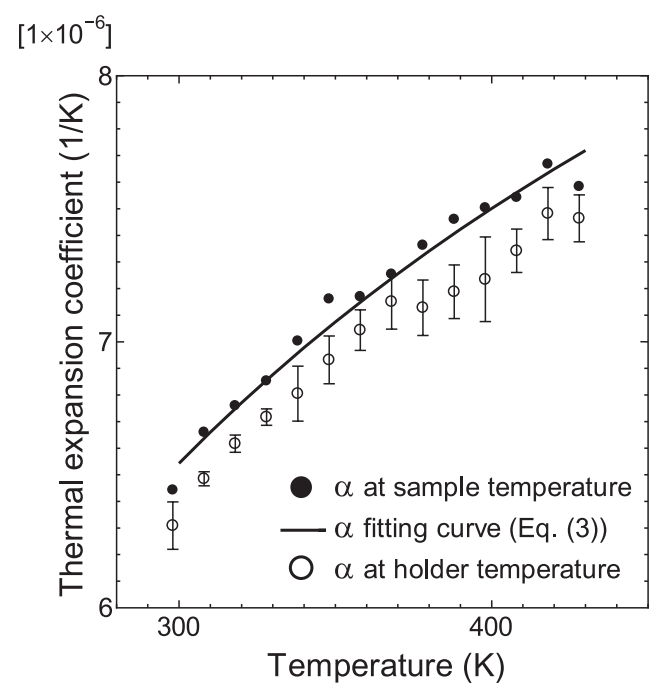

Fig. 4 Temperature dependence of the thermal expansion coefficient of YAG ceramics. The closed and open circles are the thermal expansion coefficient analyzed by using the sample and holder temperatures, respectively. The solid line shows a fitting curve from Eq. (3). $\pm 2.17 \times 10^{-8} 1 / \mathrm{K}$ であった，測定誤差は繰り返し測定した 結果の標準偏差を表している。各温度における熱澎張係 数の結果を文献11) と同様に以下の式でフィッティング した.

$$
\alpha(T)=A \exp \left(-\frac{B}{T}\right)
$$

式中の值は $A=1.13 \times 10^{-5} 1 / \mathrm{K}, B=163.9 \mathrm{~K}$ である.

\section{2 熱光学係数の解析結果}

Fig. 5 にYAGセラミックスの熱光学係数の測定結果を 示す. $\square$ は試料(B)を波長1064 nmのレーザーを用いて 測定した結果を示している。，○はそれぞれ試料 $(\mathrm{A})$ ， (B) をHe-Neレーザーを用いて測定した結果を示してい る. 熱光学係数の算出には式(3)で示した熱膨張係数の フィッティング值を使用した。また参考のために， YAG単結晶における熱光学係数(1064 nm)の文献值12) を記した。

Fig. 5 に示すように熱光学係数は温度とともに増加し た。また波長1064 nmと632.8 nmでは1064 nmの方が小さ

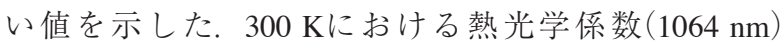

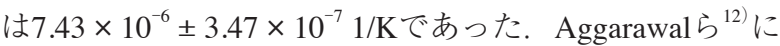
よって報告されたYAG単結晶における同波長の值 は, $7.8 \times 10^{-6} \pm 4.0 \times 10^{-7} 1 / \mathrm{K}$ であり, 我々の測定結果と 誤差の範囲内で一致した。

Fig. 5 中の実線は波長1064 nmの熱光学係数のフィッ ティング曲線であり, 以下の式から算出した.

$$
\frac{d n}{d T}(T)=N_{0}+N_{1} T+N_{2} T^{2}+N_{3} T^{3}
$$

ここで, $N_{0}=-9.87 \times 10^{-6} \mathrm{~K}^{-1}, \quad N_{1}=7.77 \times 10^{-8} \mathrm{~K}^{-2}, \quad N_{2}=$ $-5.75 \times 10^{-11} \mathrm{~K}^{-3}, N_{3}=-3.05 \times 10^{-14} \mathrm{~K}^{-4}$ である.

$\left[1 \times 10^{-6}\right]$

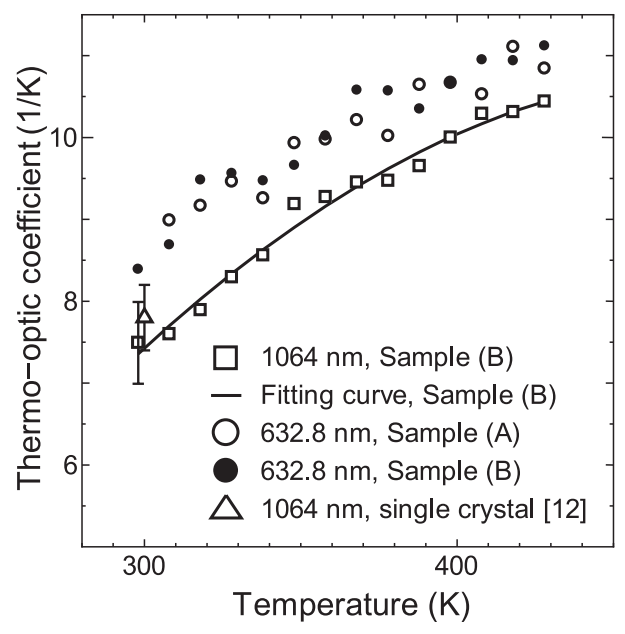

Fig. 5 Temperature dependence of the thermo-optic coefficient of YAG ceramics. The square shows the results for $\lambda=1064 \mathrm{~nm}$, and the solid line shows a fitting curve. The open and solid circles represent the results at $\lambda=632.8 \mathrm{~nm}$ for sample (A) and (B), respectively. 
一方, 試料 $(\mathrm{A})$, (B) を用いて測定した熱光学係数 (632.8 nm)の温度特性はほぼ同等であった。このことよ り, 光路長の異なる試料でも再現性が確かめられた。

Table 1 に透光性YAGセラミックスの熱膨張係数, 熱 光学係数の值をまとめた. 各波長の $300 \mathrm{~K}$ の熱光学係数 に注目すると波長1064 nmでは632.8 nmより0.87倍小さ くなっている。さらに632.8, $1064 \mathrm{~nm}$ における熱光学係 数をそれぞれ $300 \mathrm{~K}$ と $400 \mathrm{~K} て ゙$ 比較すると, $632.8 \mathrm{~nm}$ 光で は1.26倍に増加するのに対して, $1064 \mathrm{~nm}$ 光では1.35倍 に増加した。 したがって熱光学係数は今回の測定温度領 域では1064 nmの方が小さくなることが分かったが，一 方で温度に対する変化率が大きいために, 熱収差等の問 題がより顕著に表れると考えられる。これは高出力レー ザー設計に重要な知見といえる。

\section{3 熱レンズ効果の見積もり}

今回測定した熱光学係数の温度特性を用いて, 厚 み $2 \mathrm{~cm}$ の透光性YAGセラミックスにビーム径 $\phi 5 \mathrm{~cm}$ の高 出力レーザーを導入した際にどの程度の熱レンズ効果が 生じるかを見積もった，YAGセラミックスの温度 が300 K, $400 \mathrm{~K}$ の場合についてそれぞれ計算を行い, 結 果を比較した。

熱レンズ焦点距離 $f$ 計算には，以下の式を用いた ${ }^{13)}$.

$$
\frac{1}{f}=\frac{L a_{0} P_{i n}}{2 \pi r_{h}^{2} K}(P-1 / 5(1-\xi) Q)
$$

ここでLは媒質長， $a_{0}$ は吸収係数， $P_{\text {in }}$ はレーザーパワー, $r_{\mathrm{h}}$ はビーム半径, $K$ は熱伝導率, $\xi$ は異方性パラメータで ある。（5）式では発熱に寄与するレーザー光の空間強度 分布が正規分布であり，媒質の吸収係数が十分に小さ く，厚さ方向の発熱分布が一様であると仮定されてい る。また $P, Q$ は以下の式で与えられる熱光学パラメー 夕である ${ }^{14)}$

$$
\begin{gathered}
Q=\alpha \frac{n^{3}}{4} \frac{1+v}{1-v}\left(P_{11}-P_{12}\right) \\
P=\frac{d n}{d T}-\alpha \frac{n^{3}}{4} \frac{1+v}{1-v}\left(P_{11}+P_{12}\right)
\end{gathered}
$$

ここでりはポアソン比, $P_{\mathrm{ij}}$ は光弾性テンソルである. 計 算では以下の值を使用した： $L=2.0 \mathrm{~cm}, a_{0}=3.0 \times$
$10^{-3} \mathrm{~cm}^{-1}, \quad r_{\mathrm{h}}=2.5 \mathrm{~cm}, \quad K(300 \mathrm{~K})=12.6 \mathrm{~W} / \mathrm{mK}, \quad K(400 \mathrm{~K})$ $=10.6 \mathrm{~W} / \mathrm{mK}^{6)}, \quad \xi=3.2^{15)}, \quad n=1.816348, \quad v=0.23^{9)}, \quad p_{11}=$ $-0.029, p_{12}=0.0091^{16)} . \alpha$ dn/dTにはTable 1 の值を用 い, 入力パワーPinを1-10 kWに変化させた場合の熱レ ンズ焦点距離を計算した。

Fig. 6 に熱レンズ焦点距離と入力パワーの関係を示 す。図中の実線と破線はそれぞれ温度 $300 \mathrm{~K}$ と $400 \mathrm{~K}$ の結 果を示している，どちらの結果も入力パワーが大きくな るにしたがって焦点距離は短くなり，熱レンズ効果が強 くなることが分かる。また $400 \mathrm{~K}$ の結果の方が熱レンズ 焦点距離が短く，入力パワー $1 \mathrm{~kW}$ では約 1.6 倍の差が生 じた。

今回の熱レンズ効果の見積もりでは無添加YAGセラ ミックスを想定しているために吸収係数が小さく，入力 パワー10 kW導入した場合においても熱レンズ焦点距離 は100 m程度である。一方, $\mathrm{Yb}$ や Nd等の活性元素を添加 した典型的なレーザー材料では吸収係数が約 3 桁程度増 加するため、発熱量に応じて強い熱レンズ効果が生じる と考えられる。今後, $\mathrm{Yb}$ やNd等の活性元素添加YAG七 ラミックスにおける詳細な熱解析を行うためには, 熱伝 導率, 熱澎張係数および熱光学係数の添加濃度依存性に ついても明らかにする必要がある。

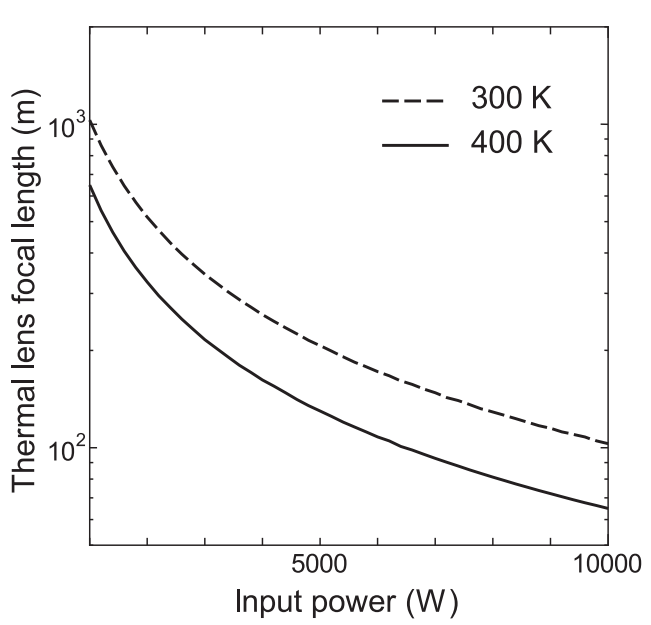

Fig. 6 Calculations of the thermal lens focal length as a function of input laser power. The solid and dashed lines show the results for $300 \mathrm{~K}$ and $400 \mathrm{~K}$, respectively.

Table 1 Fitted values of $\alpha$ and $\mathrm{dn} / \mathrm{dT}$ of transparent YAG ceramics.

\begin{tabular}{cccc}
\hline $\mathrm{T}(\mathrm{K})$ & $d n / d T\left(\times 10^{-6}\right)(1 / \mathrm{K})$ & $\begin{array}{c}d n / d T\left(\times 10^{-6}\right)(1 / \mathrm{K}) \\
\lambda=632.8 \mathrm{~nm}\end{array}$ & $\begin{array}{c}d n / d T\left(\times 10^{-6}\right)(1 / \mathrm{K}) \\
\lambda=1064 \mathrm{~nm}\end{array}$ \\
\hline 300 & 6.56 & 8.52 & 7.43 \\
320 & 6.78 & 9.21 & 8.10 \\
340 & 6.99 & 9.74 & 8.69 \\
360 & 7.18 & 10.1 & 9.21 \\
380 & 7.35 & 10.5 & 9.66 \\
400 & 7.51 & 10.7 & 10.0 \\
\hline
\end{tabular}




\section{4. まとめ}

我々は高出力レーザー設計に役立てるため, 透光性 YAGセラミックスの熱光学係数の測定を行った。波 長1064 nmに対する熱光学係数を室温-430 Kの温度範囲 で求め, その温度特性を初めて明らかにした。可視域と 比較し, 近赤外域の方が熱光学係数が小さくなったが, 温度に対する増加率は大きくなることを明らかにした。

今後はYbやNd等の活性元素の添加濃度依存性 や1550 nm等の光源を用いて研究を行い, 温度 · 波長依 存性をより詳細に明らかにすることが必要である。

\section{5. 謝 辞}

本研究の一部は自然科学研究機構核融合科学研究所の 一般共同研究 (NIFS15KBAH010)のもとに実施された.

\section{6. 参考文献}

1) S. Banerjee, P. D. Mason, K. Ertel, P. J. Phillips, M. D. Vido, O. Chekhlov, M. Divoky, J. Pilar, J. Smith, T. Butcher, A. Lintern, S. Tomlinson, W. Shaikh, C. Hooker, A. Lucianetti, C. H. Gomez, T. Mocek, C. Edwards, and J. L. Collier: Opt. Lett. 41 (2016) 2089.
2) G. Novo, D. Albach, B. Vincent, M. Arzakantsyan, and J. C. Chanteloup: Opt. Express 21 (2013) 855.

3) M. Divoky, S. Tokita, S. Hwang, T. Kawashima, H. Kan, A. Lucianetti, T. Mocek, and J. Kawanaka: Opt. Lett. 40 (2015) 855.

4) Y. Sato and T. Taira: Opt. Express 14 (2006) 10528.

5) R. Wynne, J. L. Daneu, and T. Y. Fan: Appl. Opt. 38 (1999) 3282.

6) R. Yasuhara, H. Furuse, A. Iwamoto, J. Kawanaka, and T. Yanagitani: Opt. Express 20 (2012) 29531

7) T. Y. Fan, D. J. Ripin, R. L. Aggarwal, J. R. Ochoa, B. Chann, M. Tilleman, and J. Spitzberg: IEEE J. Sel. Top. Quantum Electron. 13 (2007) 448.

8) D. C. Brown: IEEE J. Sel. Top. Quantum Electron. 11 (2005) 587.

9) H. Yagi, T. Yanagitani, T. Numazawa, and K. Ueda: Ceram. Int. 33 (2007) 711.

10) Y. Sato, J. Akiyama, and T. Taira: Opt. Mater. 31 (2009) 720.

11) H. Furuse, R. Yasuhara, and K. Hiraga: Opt. Mater. Express 4 (2014) 1794.

12) R. L. Aggarwal, D. J. Ripin, J. R. Ochoa, and T. Y. Fan: J. Appl. Phys. 98 (2005) 103514.

13) I. L. Snetkov, D. E. Silin, O. V. Palashov, E. A. Khazanov, H. Yagi, T. Yanagitani, H. Yoneda, A. Shirakawa, K. Ueda, and A. A. Kaminskii: Opt. Express 21 (2013) 21254.

14) E. A. Khazanov, O. V. Kulagin, S. Yoshida, D. B. Tanner, and D. H. Reitze: IEEE J. Quantum Electron. 35 (1999) 1116.

15) H. Furuse, R. Yasuhara, and K. Hiraga: Opt. Mater. Express. 5 (2015) 1266.

16) W. Koechner: Solid-State Laser Engineering ed. W. T. Rhodes (Springer, 2006) p. 441. 